\title{
Gynecological Cancers: A Challenge of Individualized Therapy in the Adjuvant and Palliative Setting
}

Cancers of the female reproductive organs are among the most common neoplastic diseases in women. In industrialized countries breast cancer is the most frequent malignancy ahead of endometrial cancer followed by ovarian and cervical cancer. While the overall survival of patients suffering from gynecological cancers has increased by measures of early screening and optimized adjuvant and palliative therapy, the demanding question is to individualize treatment taking in account greatest effectiveness and acceptable toxicity. Individualized therapy does not only mean to indicate a therapy according to upto-date recommendations - therapies ought to be applied in clinical trials in order to determine the actual effectiveness and toxicities of therapies.

In a pooled analysis by Look et al. [1] the invasion markers urokinase-type plasminogen activator (uPA) and its inhibitor PAI-I have recently been shown to be critical components in disease progression in breast cancer. They have been demonstrated to be indicators of poor prognosis. Patients with nodenegative breast cancer identified to be at higher risk of relapse by high tumor levels of UPA and PAI-I have been treated in a prospective, multicenter trial to evaluate the benefit of additional chemotherapy. In an article about the clinical relevance of prognostic factors Thomssen and colleagues [2] critically discuss the role of UPA and PAI-I in breast cancer.

Type 1 endometrial cancer can be detected in early stages by the presence of postmenopausal bleeding. This is less the case for type 2 endometrial cancer. Besides a sufficient surgical treatment radiation therapy takes a great part in postsurgical therapy. Furthermore, Hanf and colleagues [3] point out that in stage III and node-positive endometrial cancer chemotherapy with platinum agents, taxanes, and anthracyclines offers a more effective therapy option and leaves radiation as a secondary treatment option, as chemotherapy after primary radiation might not be as effective.

Pfisterer et al. [4] emphasize that ovarian cancer still remains a tumor entity which primarily requires a profound surgical staging followed by a platinum containing chemotherapy even in early stages. Most of the patients are older and have advanced stages at the time of diagnosis. But insufficient surgery leads to underestimation of tumor stage and a high load of tumor residues worsening the overall prognosis, as postsurgical chemotherapy cannot compensate for inadequate surgery. Locally advanced or relapsed cervical cancer is often associated with local complications such as infiltration of adjacent organs and fixation to the pelvic wall. Surgical approaches to this situation are usually confined to centrally located tumor masses after prior radiation therapy. Infiltration of the pelvic walls signified inoperability. A new promising method introduced by Höckel [5] is the laterally extended endopelvic resection (LEER) which offers better chances for long-term survival even in these cases.

The broad spectrum of individualized tumor therapy demonstrated by the topics above show the importance of exact tumor staging in the adjuvant and palliative setting and the necessity to confine oncologic therapy to specialized centers with the required infrastructure and well-trained staff.

Rolf Kreienberg, Ulm

\section{References}

1 Look MP, van Putten WL, Duffy MJ, Harbeck N, Christensen IJ, Thomssen C, Kates R, Spyratos F, Ferno M, Eppenberger-Castori S, Sweep CG, Ulm K, Peyrat JP, Martin PM, Magdelenat H, Brunner N, Duggan C, Lisboa BW, Bendahl PO, Quillien V, Daver A, Ricolleau G, Meijer-Van Gelder ME, Manders P, Fiets WE, Blankenstein MA, Broet P, Romain S, Daxenbichler G, Windbichler G, Cufer T, Borstnar S, Kueng W, Beex LV, Klijn JG, O'Higgins N, Eppenberger U, Janicke F, Schmitt M, Foekens JA: Pooled Analysis of Prognostic Impact of UrokinaseType Plasminogen Activator and Its Inhibitor PAI-1 in 8377 Breast Cancer Patients. J Natl Cancer Inst 2002;294:116-128.

2 Thomssen C, Jänicke F, Harbeck N: Clinical relevance of prognostic factors in axillary node-negative breast cancer. Onkologie 2003;26:438-445.

3 Hanf V, Günthert AR, Emons G: Endometrial cancer. Onkologie 2003;26:429436.

4 Pfisterer J, Hilpert F, du Bois A, Meier W, Wagner U: State-of-the-art first-line treatment of ovarian cancer. Onkologie 2003;26:446-450.

5 Höckel M: Surgical treatment of locally advanced and recurrent cervical carcinoma: Overview on current standard and new developments. Onkologie 2003;26: $425-455$.

\begin{tabular}{ll}
\hline KARGER & @ 2003 S. Karger GmbH, Freiburg \\
Fax +497614520714 & Accessible online at: \\
$\begin{array}{l}\text { E-mail Information@Karger.de } \\
\text { www.karger.com }\end{array}$ & www.karger.com/onk
\end{tabular}

Prof. Dr. med. Rolf Kreienberg 